\title{
COMPORTAMENTO INGESTIVO DIURNO DE VACAS GIROLANDAS, SOB DIFERENTES TAXAS DE LOTAÇÃO
}

\author{
DIURNAL INTAKE BEHAVIOR OF GIROLANDA COWS AT DIFFERENT \\ STOCKING RATES
}

\author{
Silva, A.M. ${ }^{1}$, Modesto, E.C. ${ }^{2}$, Lira, C.C. ${ }^{1}$, Santos, M.V.F. ${ }^{3}$, Brasil, L.H.A. ${ }^{3}$, Lira, M.A. ${ }^{4}$, \\ Dubeux Júnior, J.C.B. ${ }^{3}$ e Mello, A.C.L. ${ }^{3}$
}

\begin{abstract}
'Universidade Federal Rural de Pernambuco. UFRPE. Brasil. andrezzamiguel@hotmail.com; camaralira@gmail.com

2UFRRJ. Rio de janeiro. Brasil. ecmodesto@gmail.com

3UFRPE/PPGZ. Recife. Brasil. mercia@dz.ufrpe.br; lubrasil@dz.ufrpe.br; dubeux@dz.ufrpe.br; Mello@dz.ufrpe.br

4IPA. Recife. Brasil.mlira@terra.com.br
\end{abstract}

PalaVRas ChaVe ADICIONAIS

Ócio. Pastejo. Ruminação. Temperaturas.

\section{RESUMO}

Objetivou-se verificar o comportamento de vacas em diferentes taxas de lotação (2, 4 e 6 UA), em pastejo rotacionado. $O$ delineamento experimental utilizado foi blocos ao acaso em arranjo de parcelas subdivididas com medidas repetidas no tempo, com três repetições. As observações do comportamento ingestivo dos animais foram realizadas de $10 \mathrm{em} 10$ minutos durante o período diurno. O tempo de pastejo, ruminação, ócio e de outras atividades dos animais foi afetado pelo período de avaliação, dia de pastejo e taxa de lotação. Verificou-se a presença de correlação negativa entre o tempo de pastejo e tempo de ruminação, de ócio, outras atividades, índice de temperatura e umidade (ITU) e índice de temperatura globo e umidade (ITGU). Durante os períodos em que ocorreu precipitação pluviométrica os animais apresentaram comportamento de pastejo semelhante (tempo de pastejo médio de 434 minutos), o que permitiu o uso de ambas as lotações, sem maiores danos ao comportamento dos animais, no período chuvoso do ano.

\section{SUMMARY}

The behavior of cows at different stocking rates $(2,4$ and $6 \cup A)$, in rotational grazing was studied. The experimental design was randomized

\section{Additional KEYWORDS}

Leisure. Grazing. Ruminating. Temperatures. blocks in an split plot arrangement with repeated measures and three repetitions. Observations of feeding behavior of the animals were held every 10 minutes during the daytime. Grazing, rumination, and other activities of the animals were affected by period of grazing, days of grazing and stocking rate. There were negative correlations between grazing time of animals and the variables: rumination time, leisure, other activities, temperature and humidity index (ITU) and black globe-humidity index (ITGU). During periods when rainfall occurred the animals showed similar behavior of grazing (grazing time average of 434 minutes), which allowed the use of both stocking rates, without much damage to the behavior of the animals in the rainy season.

\section{INTRODUÇÃO}

O conhecimento do comportamento dos animais é essencial para a obtenção de condições ótimas de criação e alimentação (Swenson, 1996) e pelas recentes demandas da sociedade em relação ao bem-estar dos animais (Carvalho, 2005).

Para sobreviver em um ambiente de pastagem e ainda interagir com estes dife- 
rentes tipos de estrutura, os herbívoros desenvolveram uma série de mecanismos de pastejo que compõem o que se chama de comportamento ingestivo, os quais permitem aos mesmos colherem, de forma geral, uma dieta de qualidade superior àquela presente na média no ambiente (Carvalho et al., 1999).

O comportamento ingestivo pode ser afetado por fatores ligados ao alimento, ao ambiente e ao animal (Fischer et al., 2002), e através do comportamento em pastejo, o animal é capaz de demonstrar as características de seu ambiente pastoril, podendo assim tornar-se uma importante ferramenta de gestão do animal no pasto (Carvalho e Moraes, 2005).

A caracterização do comportamento ingestivo se dá através da distribuição desuniforme de uma sucessão de períodos definidos e discretos de atividades, comumente classificadas como ingestão, ruminação e descanso ou ócio (Penning et al., 1991). E quando o animal está em pastejo, o processo pode ser descrito por variáveis que o compõem entre essas: o tempo de pastejo, taxa de bocados e massa de bocados (Carvalho et al., 2001), sendo, o consumo de forragem do animal em pastejo, o produto dessas variáveis (Hodgson, 1985).

O tempo de pastejo é uma variável inversamente relacionada ao consumo, quanto maior a abundância de forragem, menor o tempo de pastejo observado (Carvalho e Moraes, 2005).

Os bovinos são animais gregários e embora a vida em grupo traga uma série de vantagens adaptativas, essa também traz o aumento na competição por recursos, principalmente quando escassos (Paranhos da Costa e Nascimento Jr., 1986). Alta taxa de lotação pode levar aos animais apresentarem maior comportamento competitivo, podendo assim ocorrer modificações no seu comportamento ingestivo.

O ajuste de lotação é uma prática de manejo que visa mediar às necessidades do pasto e dos animais para a obtenção da máxima produtividade por animal ou por área, sem prejudicar a pastagem (Modesto et al., 2008) e possibilitar a distribuição normal diária do comportamento ingestivo em pastejo, bem como o seu bem-estar.

O ajuste de lotação é uma prática de manejo que visa mediar às necessidades do pasto e dos animais para a obtenção da máxima produtividade por animal ou por área, sem prejudicar a pastagem (Modesto et al., 2008). E ainda possibilitar a distribuição normal diária do comportamento ingestivo dos animais em pastejo, bem como o seu bem-estar.

Dessa forma, objetivou-se avaliar o comportamento ingestivo de vacas da raça Girolando, em pastagem de Brachiaria decumbens, sob três taxas de lotação e diferentes períodos de avaliação, na região da Zona da Mata de Pernambuco, Brasil.

\section{MATERIALE MÉTODOS}

O experimento foi realizado no Instituto Agronômico de Pernambuco (IPA), em Itambé-PE, microrregião fisiográfica Zona da Mata Seca de Pernambuco (Brasil), no período de Agosto de 2007 a Julho de 2008. O município de Itambé localiza-se nas coordenadas geográficas $7^{\circ} 25^{\prime} 00^{\prime \prime}$ de latitude e $35^{\circ} 06^{\prime} 00^{\prime \prime}$ de longitude, a $190 \mathrm{~m}$ de altitude.

Os tratamentos foram constituídos por diferentes taxas de lotação (2, 4 e 6 UA, o que corresponde a um peso vivo de $450 \mathrm{~kg}$ ) sob pastagem de Brachiaria decumbens e cada bloco experimental foi constituído por três piquetes, sem sombreamento.

Utilizou-se o método de pastejo rotacionado, com taxa de lotação fixa, com período de ocupação de três dias e de descanso de 67 (estação seca) e 32 dias (estação chuvosa). O delineamento experimental adotado foi o de blocos inteiramente casualisados com três repetições, onde a parcela principal foi constituída pela lotação animal, a subparcela pelos dias de pastejo, sendo as diferentes avaliações consideradas medidas repetidas no tempo. A área foi dividida em blocos experimentais, devido à 


\section{COMPORTAMENTO INGESTIVO DIURNO DE VACAS GIROLANDAS}

heterogeneidade do terreno (inclinação e características químicas do solo). Todos os 9 piquetes experimentais eram formados por capim Brachiaria decumbens Stapf. (com cerca de $833 \mathrm{~m}^{2}$ ) dotados de bebedouro com bóia flutuante.

Foram utilizadas 12 vacas multíparas em cada período de pastejo, da raça Girolando -5/8 Holandes x Zebu (5/8 HZ), com peso médio corporal de $496 \mathrm{~kg}$ e produção média de $5,00 \mathrm{~kg} /$ leite $/$ dia. As vacas eram ordenhadas manualmente uma vez ao dia, com bezerro ao pé. Após a realização da ordenha, os bezerros permaneciam juntos com a mãe por cerca de 1 hora e 30 minutos e em seguida as vacas retornavam a pastagem.

Os animais permaneciam durante toda a noite nos piquetes e por volta das 5 horas da manhã eram conduzidos para o estábulo para realização da ordenha, com sal mineral à disposição, onde permaneciam cerca de 4 horas. Terminado o manejo da ordenha os animais retornavam para os piquetes, momento em que eram iniciadas as observações e registro das atividades comportamentais permanecendo por cerca de 9 horas consecutivas. Para a identificação dos animais, realizou-se a marcação com o uso de tinta spray na garupa e no dorso do animal, além das próprias características morfológicas (como pelagem) individuais do animal.

As atividades comportamentais observadas foram: pastejo, ruminação, ócio e outras, que incluíam as atividades de andar, beber e se lamber.

Os períodos de avaliação do comportamento ingestivo dos animais ocorreu durante sete ciclos de pastejo, referente aos meses de Agosto/2007 (período 1), Outubro/ 2007 (período 2), Novembro/2007 (período 3), Março/2008 (período 4), Maio/2008 (período 5), Junho/2008 (período 6) e Julho/ 2008 (período 7).

Para o registro do comportamento dos animais, usou-se o método de coleta instantânea e de forma contínua e amostragem pelo método focal (Martin e Bateson, 1986), com intervalos de dez minutos (Silva et al.,
2006), feita durante o período diurno, em cada bloco e dia de pastejo, por três observadores. Foi observado cada animal e identificada à atividade naquele momento.

O monitoramento do ambiente foi realizado a cada intervalo de 1 hora, obtido por meio de uma estação meteorológica instalada no local do experimento, próxima a área de pastejo dos animais. A estação possuía em seu interior um psicrômetro (medição de temperatura de bulbo seco e úmido) e termômetro de máxima e mínima. Em local adjacente a estação meteorológica, com ausência de cobertura, instalou-se o termômetro de globo negro a 1,20 m (considerando a altura média de bovinos adultos) acima do solo. Para determinação da umidade relativa do ar (UR), utilizaram-se tabelas meteorológicas, com base nos registros das temperaturas dos bulbos seco e úmido, obtendo-se valores percentuais. Os valores referentes à pluviometria (milímetros) foram obtidos do banco de dados da própria Estação Experimental, os quais são coletados diariamente por intermédio de um pluviômetro comum, instalado na propriedade.

Foi calculado o índice de temperatura e umidade (ITU) utilizando-se a fórmula proposta por Kelly e Bond (1971), sendo ITU $=$ Tbs - 0,55 (1 - UR) (Tbs - 58), onde Tbs é a temperatura de bulbo seco $\left({ }^{\circ} \mathrm{F}\right)$ e UR a umidade relativa do ar em decimais, obtida em tabelas meteorológicas através dos registros da temperatura do bulbo seco e do bulbo úmido. Também foi calculado o índice de temperatura de globo e umidade (ITGU) através da fórmula proposta por Buffington et al. (1981), onde o ITGU $=\operatorname{tg}+0,36$ tpo + 41,5; com a Tg representando a temperatura de globo negro em ${ }^{\circ} \mathrm{C}$ e Tpo a temperatura de ponto de orvalho em ${ }^{\circ} \mathrm{C}$. A Tpo foi calculada de acordo com a fórmula de $\mathrm{Tpo}=$ $(186,4905$ - 237,3 $\operatorname{LogPp}\{\mathrm{ta}\}) /(\operatorname{LogPp}\{\mathrm{ta}\}-$ $8,2859)$, onde $\operatorname{Pp}\{$ ta $\}$ é a pressão parcial de vapor em milibares.

A análise estatística dos dados foi feita considerando-se o delineamento em blocos ao acaso em parcelas subdivididas com 
medidas repetidas no tempo, com a parcela principal sendo a taxa de lotação, a subparcela os dias de pastejo e os diferentes períodos de pastejo as medidas repetidas. A análise de variância foi feita com o proc MIXED do SAS (SAS, 2001) em medidas repetidas no tempo. Quando verificado efeito da interação entre as variáveis independentes, bem como interação significativa (fazendo-se o desdobramento) aplicou-se o teste de Tukey. Além disso, foi realizada correlação entre todas as variáveis utilizando-se o proc correl do SAS (SAS, 2001). Para todos os procedimentos foi utilizado o nível de significância de $1 \%$.

\section{RESULTADOSEDISCUSSÃO}

Os índices calculados para caracterização do ambiente, referentes ao ITU, ITGU e a pluviosidade podem ser observados na figura 1.

Para o tempo de pastejo dos animais (figura 2) houve efeito da interação período e dia de pastejo $(\mathrm{p}=0,0001)$ e da interação período de pastejo e taxa de lotação $(\mathrm{p}=$ $0,0001)$, no entanto não foi verificada interação entre período de pastejo, dia de pastejo e taxa de lotação $(\mathrm{p}=0,2244)$.

No período de pastejo 1, 2 e 7 os animais nas três lotações apresentaram um comportamento de pastejo semelhante. Já nos demais períodos houve diferença entre os comportamentos, nas três taxas de lotação (figura 2).

Na maior parte do período experimental, os animais na taxa de lotação 4 UA apresentaram comportamento de pastejo mais homogêneo, em relação ao tempo dos animais nas demais lotações, exceto pelo período 4 , onde as lotações 4 e 6 apresentaram comportamento semelhante. Devido a taxa de lotação e a disponibilidade de forragem, os animais na taxa de lotação 4 UA pastejaram por mais tempo, enquanto que na lotação 6 UA além da taxa de lotação, a seletividade aumentou a competitividade entre os animais.

Vale destacar que os períodos onde os animais apresentaram grande variação no comportamento de pastejo foram aqueles, onde ocorreu baixa precipitação pluviométrica ou aumento da temperatura ambien-

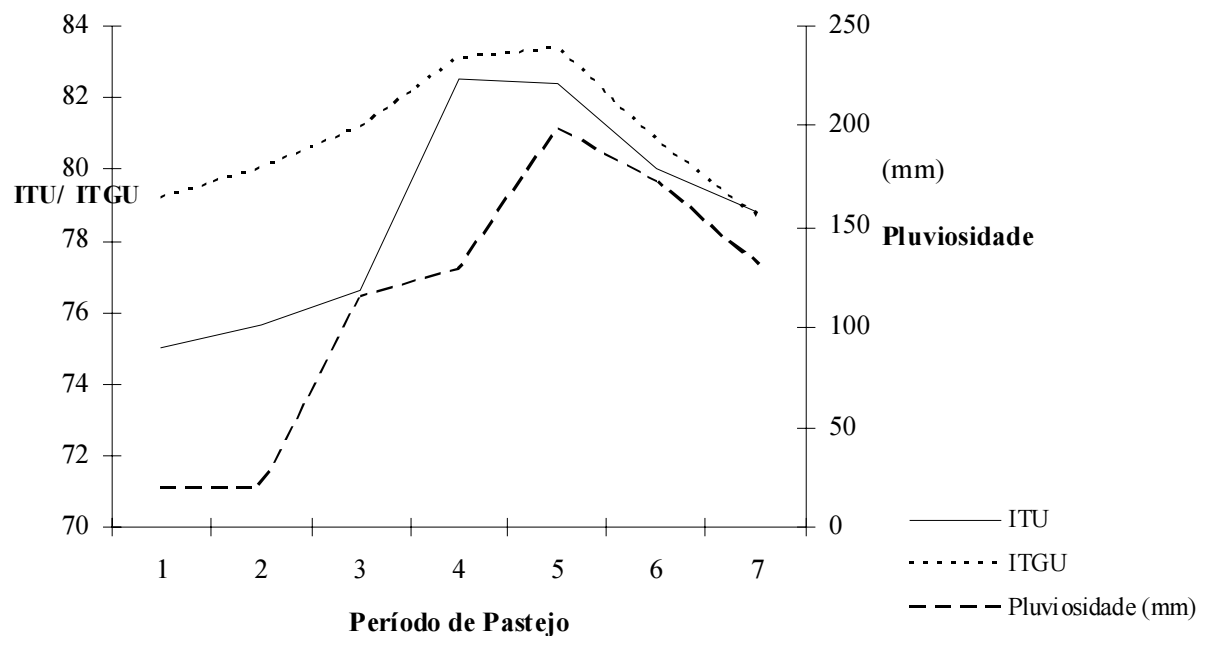

Figura 1. Monitoramento do ambiente durante o periodo experimental de vacas Girolandas em pastagem de Brachiaria decumbens. (Environmental parameters during the trial period). 


\section{COMPORTAMENTO INGESTIVO DIURNO DE VACAS GIROLANDAS}

abtaxas de lotação, em cada período, são diferentes $(p<0,01)$ pelo teste de Tukey
CV:Período de pastejo (15\%)

CV:Taxa de lotação (16\%)

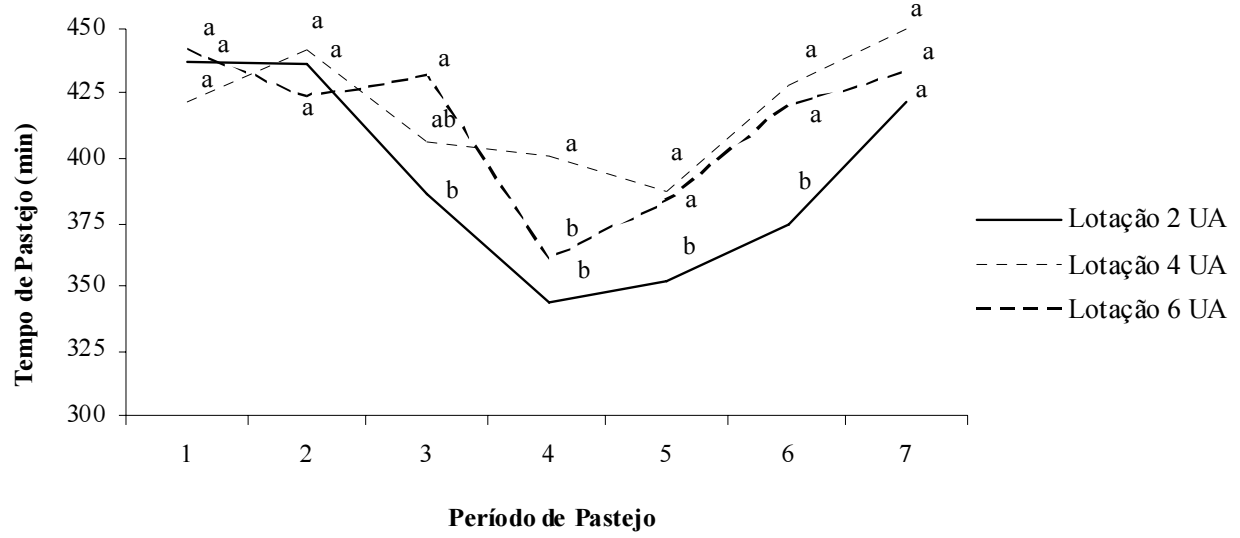

Figura 2. Tempo de pastejo diurno de vacas Girolandas em pastagem de B. decumbens, submetidas a três taxas de lotação, em diferentes períodos de pastejo. (Grazing time of Girolanda cattle on $B$. decumbens pasture, submitted to three stocking rates in different grazing periods).

te (figura 1), períodos estes onde alterações na qualidade e quantidade do pasto são esperadas. Fora destes períodos, os animais apresentaram comportamento de pastejo semelhante, o que possibilita o uso de uma das lotações (2, 4 e 6 UA), sem a ocorrência de danos ao comportamento dos animais.

A diferença encontrada para a atividade de pastejar, nos diferentes períodos de pastejo, deve-se provavelmente a variações em termos qualitativos do pasto e também às variáveis climatológicas. A baixa pluviosidade observada nos períodos 1 e 2 , pode ter refletido negativamente sobre as características do pasto, uma vez que seu aumento iniciou a partir do período 3 , fazendo com que os animais reduzissem o tempo de pastejo. Nos períodos 4 e 5, verificou-se maiores valores de ITU e ITGU, além disso, no período 4 teve aumento no intervalo do ciclo de pastejo, onde redução na qualidade do pasto é esperada.

Grant e Albright (1995) ressaltam que animais submetidos ao estresse calórico reduzem o número e a duração das refeições diárias, uma vez que em sistema de pastejo, a temperatura parece ser o fator do meio determinante do consumo, pois influencia o apetite (Silva e Leão, 1979).

No sétimo período de pastejo, o tempo destinado ao pastejo, por parte dos animais, volta a apresentar comportamento semelhante, nas diferentes lotações, período esse em que o pasto já se encontrava recuperado.

Maior densidade animal por piquete está relacionada a um maior rebaixamento da altura do pasto. A altura do dossel tem reflexo importante sobre a acessibilidade da forragem aos animais (Montagner et al., 2003), onde em condições de baixa oferta de forragem, o animal tende a aumentar o tempo de pastejo (Gordon e Lascano, 1993), na tentativa de atender suas exigências nutricionais diárias.

O tempo de pastejo (figura 3) foi maior no terceiro dia de pastejo na pastagem (períodos de pastejo 1, 2 e 6). Com o passar do dia de pastejo, os animais tendem a aumentar esse tempo, na tentativa de atender suas exigências nutricionais. Nos períodos 5 e 7 , os animais apresentaram comportamento de pastejo semelhante, durante os três dias de pastejo. Nos demais períodos (3 e 4) o 
${ }^{\mathrm{ab} o s}$ dias de pastejo, em cada período, são diferentes $(p<0,01)$ pelo teste de Tukey

CV:Período de pastejo (15\%) CV: Dia de pastejo (16\%)

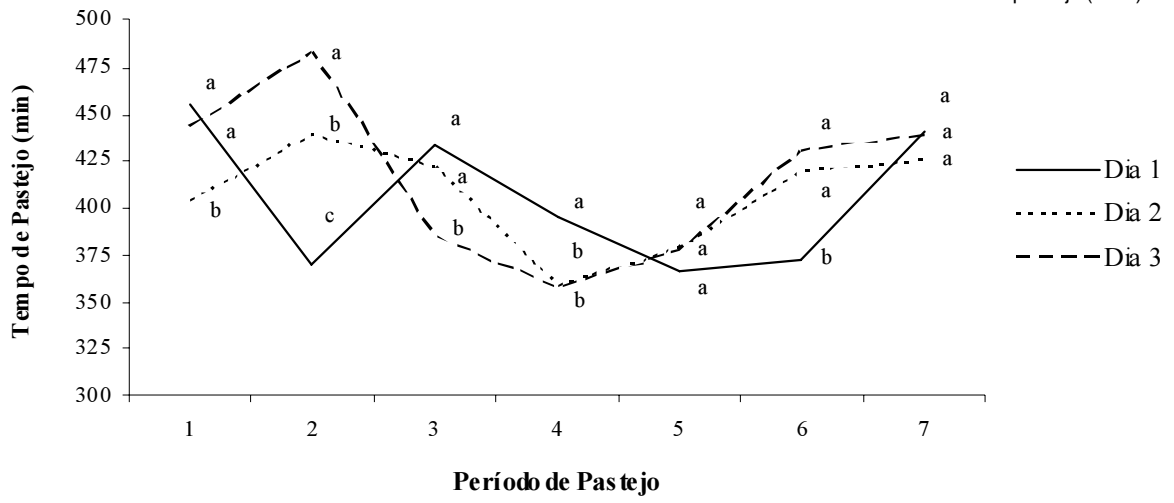

Figura 3. Tempo de pastejo diurno de vacas Girolandas em pastagem de B. decumbens, nos diferentes períodos e dias de pastejo. (Grazing daytime of Girolanda cattle on pasture of $B$. decumbens in different periods and days of grazing).

tempo de pastejo em função do dia de pastejo apresentou uma maior variação (figura 3). Possível efeito residual do dia de pastejo anterior pode ter ocorrido, fazendo com que os animais aumentassem seu tempo de pastejo, como medida para suprir sua demanda nutricional, limitada no terceiro dia de pastejo pelas condições do pasto.

Diariamente os animais atuaram balanceando o seu tempo de pastejo, em função do gasto energético que tinham, definindo qual atividade é a mais econômica energeticamente, sendo essa decisão função das condições do meio em que se encontra. Os animais podem reconhecer o valor energético dos alimentos e podem avaliar o custo energético de obter alimento, quando organizam seu comportamento de alimentação (Broom e Fraser, 2007), sendo um caráter adaptativo (Graig, 1981).

O tempo de pastejo médio encontrado nesse trabalho, $\pm 7,0$ horas, encontra-se dentro da faixa de valores citados por Fraser (1980), Hodgson (1990) e Pires et al. (2001), que mencionam tempo disponibilizado para o consumo de alimentos variando de quatro a dez horas por dia.

O tempo de pastejo dos animais apresentou correlação negativa $(\mathrm{p}<0,01)$ com o tempo de ruminação, de ócio, outras atividades, ITU e ITGU (tabela I). Considerando que as atividades comportamentais dos animais são mutuamente excludentes (Costa et al., 2003), com o animal realizando um único comportamento a cada momento, maior tempo destinado a certa atividade, fará com que as demais tenham sua realização limitada

Nesse sentido, as atividades comportamentais apresentam caráter competitivo ao longo do dia do animal, sendo esse caráter controlado por fatores como: o próprio animal, a pastagem e os elementos climáticos, ficando a distribuição do seu padrão comportamental diário na dependência desses fatores. Para um padrão comportamental normal, que satisfaça as exigências do animal em termo de alimentação, descanso, e interação social, é necessário que estes fatores estejam em equilíbrio.

Cabe ao homem principal articulador dos sistemas de criação, o qual o animal está inserido, manejar esse ambiente de forma que os efeitos negativos propiciados pelas condições ambientais, que não podem ser atenuadas por ele, sejam minimizados na tentativa de promover o bem estar dos animais. 
Quanto ao tempo de ruminação (tabela II), observou-se interação significativa entre taxa de lotação, período e dia de pastejo $(p=0,0005)$. Maior tempo de ruminação foi observado no dia 1 no período 6 para os animais nas taxas de lotação 2 e 6 UA, respectivamente. A menor e a maior densidade animal por piquete levam provavelmente ao acúmulo de material com grande teor de fibra, sendo esperado maior tempo de ruminação. Além disso, na taxa de lotação 2 UA, os animais tem a possibilidade de atender suas exigências nutricionais em um menor tempo, fazendo com que esses iniciem mais rápido a ruminação. Os animais na lotação 4, no segundo dia de pastejo, apresentaram tempo de ruminação semelhante aos das lotação 2 e 6 UA (período 2). Já no período 6 , os animais presentes na lotação 2 UA apresentaram maior tempo de ruminação. Esse mesmo comportamento foi observado no período 1, no terceiro dia de pastejo. Na lotação 6 UA, o tempo destina- do a ruminação, no terceiro dia de pastejo, por parte dos animais, não diferiu do tempo nas demais lotações.

Menores tempos de ruminação para os animais presentes nas lotações 4 e 6 UA se deu provavelmente devido a menor quantidade de massa de forragem a que estes animais foram submetidos, tendo esses, dedicados maior parte do dia ao pastejo, o que possivelmente pode ter levado estes animais a destinarem o período noturno para a atividade de ruminação, por ser um horário onde a temperatura é amena. Enquanto que, os animais mantidos na lotação 2 UA, tinham a sua disposição maior disponibilidade de massa de forragem, possivelmente estes conseguiram consumir quantidade de forragem condizente com suas exigências de forma mais acessível, e em um menor tempo que os animais que estavam submetidos as demais taxas de lotação. A maior disponibilidade de forragem e menor seletividade dos animais, na taxa de

Tabela I. Coeficientes de correlação entre tempo das atividades de pastejo, ruminação, ócio, outras atividades, ITU e ITGU, de vacas Girolandas, em pastagem de B. decumbens, submetidas a três taxas de lotação, Itambé-PE. (Correlation coefficients among time of activities of grazing, ruminating, leisure, other activities, ITU and ITGU, of Girolando cows on pasture of $B$. decumbens subjected to three stocking rates, Itambé-PE.

\begin{tabular}{|c|c|c|c|c|c|c|}
\hline & Pastejo & Ruminação & Ócio & Outras atividades & ITU & ITGU \\
\hline \multicolumn{7}{|l|}{ Lotação 2UA } \\
\hline Pastejo & - & $-0,6001^{* *}$ & $-0,6616^{* *}$ & $-0,4319^{\star *}$ & $-0,5304^{\star *}$ & $-0,3715^{\star \star}$ \\
\hline Ruminação & - & - & - & - & - & - \\
\hline Ócio & - & - & - & - & $0,4600^{* *}$ & $0,4174^{* *}$ \\
\hline Outras atividades & - & - & - & - & $0,3189^{* *}$ & - \\
\hline \multicolumn{7}{|l|}{ Lotação 4UA } \\
\hline Pastejo & - & $-0,5837^{\star *}$ & $-0,7735^{* *}$ & $-0,2959^{* *}$ & $-0,2523^{* *}$ & $-0,3739^{* *}$ \\
\hline Ruminação & - & - & - & - & - & - \\
\hline Ócio & - & - & - & - & $0,2654^{* *}$ & $0,3351^{* *}$ \\
\hline Outras atividades & - & - & - & - & - & - \\
\hline \multicolumn{7}{|l|}{ Lotação 6 UA } \\
\hline Pastejo & - & $-0,7532^{* *}$ & $-0,7121^{* *}$ & $-0,3415^{\star *}$ & $-0,4616^{* *}$ & $-0,3578^{* *}$ \\
\hline Ruminação & - & - & - & - & - & - \\
\hline Ócio & - & - & - & - & $0,4698^{* *}$ & $0,4459^{* *}$ \\
\hline Outras atividades & - & - & - & - & - & - \\
\hline
\end{tabular}


lotação 2 UA, permitiu a estes destinarem maior quantidade de tempo a atividade de ruminação.

Segundo Polli et al. (1996), a distribuição da atividade de ruminação é bastante influenciada pela alimentação, já que a ruminação se processa logo após estes períodos. Quando há decréscimo da altura da superfície do pasto, com aumento da proporção caule/folha e menor massa de forragem, aumenta o tempo gasto pelos animais em pastejo, decresce proporcionalmente o tempo gasto em ruminação (Poli et al., 2001).

A maior parte da ruminação ocorre à noite, totalizando de 6 a 8 horas diárias (Broom e Fraser, 2007), períodos fora das horas mais quentes do dia, com as maiores freqüências de ruminação ocorrendo entre 22:00 e 5:00 horas (Damasceno et al., 1999). Os valores observados neste trabalho para tempo de ruminação ( \pm 1 hora) ficaram aquém dos encontrados por Farinatti et al. (2004), avaliando o habito de pastejo em pastagem nativa de vacas da raça Holandesa no terço final da lactação, no estado do Rio Grande do Sul, observaram que a taxa de ruminação variou entre 5,23 e 9,88 horas, e ao observa- do por Zanine et al. (2007) ao avaliaram o comportamento de vacas Holandês x Zebu, em Aragoiania no Goiás, que observaram tempo de ruminação em capim Brachiaria brizantha 7,95 horas e em Brachiaria decumbens de 6,45 horas. O menor tempo dedicado a atividade de ruminação verificada neste trabalho, ocorreu devido às observações terem sido realizadas no período diurno.

Observou-se interação significativa entre taxa de lotação e período de pastejo $(p=0,0096)$ e entre período e dia de pastejo $(\mathrm{p}=0,0001)$ para a variável tempo de ócio dos animais (figura 4). No primeiro período de pastejo, os animais na taxa de lotação 4 apresentaram maior tempo de ócio, não diferindo dos presentes na lotação 6. O tempo de ócio nos demais períodos e nas três taxas de lotação apresentou-se de forma semelhante. Nesses períodos, os animais na lotação 2, apresentaram um maior tempo para esta atividade, apesar de ter sido semelhante ao das demais lotações.

Nos diferentes períodos de pastejo, verificou-se que os maiores tempo de ócio ocorreram nos períodos 3, 4 e 5, respectivamente. Vale ressaltar que nesses períodos,

Tabela II. Tempo de ruminação diurna de vacas Girolandas em pastagem de B. decumbens, submetidas a três taxas de lotação, em diferentes períodos e dias de pastejo. (Rumination time of Girolando cows on pasture of $B$. decumbens subjected to three stocking rates, at different periods and days of grazing).

\begin{tabular}{|c|c|c|c|c|c|c|c|c|c|}
\hline $\begin{array}{l}\text { DP } \\
\text { TL }\end{array}$ & 2 & $\begin{array}{l}1 \\
4\end{array}$ & 6 & 2 & $\begin{array}{l}2 \\
4\end{array}$ & 6 & 2 & $\begin{array}{l}3 \\
4\end{array}$ & 6 \\
\hline PP1 & $45,00^{a}$ & $35,00^{a}$ & $30,00^{a}$ & $65,00^{\mathrm{a}}$ & $62,50^{a}$ & $68,89^{a}$ & $80,00^{a}$ & $20,00^{\mathrm{b}}$ & $21,11^{\mathrm{b}}$ \\
\hline PP2 & $81,67^{a}$ & $87,50^{a}$ & $118,33^{a}$ & $96,67^{a}$ & $56,67^{a b}$ & $46,11^{\mathrm{b}}$ & $20,00^{a}$ & $30,00^{a}$ & $28,89^{a}$ \\
\hline PP3 & $45,00^{a}$ & $58,33^{a}$ & $38,89^{a}$ & $55,83^{a}$ & $45,00^{a}$ & $34,44^{a}$ & $66,67^{a}$ & $62,50^{a}$ & $43,33^{a}$ \\
\hline PP 4 & $65,00^{a}$ & $53,33^{a}$ & $58,89^{a}$ & $61,67^{\mathrm{a}}$ & $29,17^{a}$ & $56,67^{a}$ & $135,00^{a}$ & $63,33^{b}$ & $98,89^{a b}$ \\
\hline PP5 & $83,33^{a}$ & $56,67^{a}$ & $61,67^{a}$ & $83,33^{a}$ & $55,00^{\mathrm{a}}$ & $92,78^{a}$ & $65,00^{\mathrm{a}}$ & $69,17^{a}$ & $30,00^{\mathrm{a}}$ \\
\hline PP6 & $113,3^{a}$ & $64,17^{\mathrm{b}}$ & $111,11^{\mathrm{a}}$ & $96,67^{a}$ & $48,33^{b}$ & $46,11^{\mathrm{b}}$ & $85,00^{a}$ & $33,33^{b}$ & $46,11^{\mathrm{ab}}$ \\
\hline PP7 & $90,00^{a}$ & $27,50^{\mathrm{b}}$ & $52,22^{\mathrm{ab}}$ & $73,33^{a}$ & $35,83^{a}$ & $50,00^{a}$ & $43,33^{a}$ & $54,17^{a}$ & $54,44^{a}$ \\
\hline
\end{tabular}

CV: Período de pastejo 79\%; Taxa de lotação 79\%; Dia de pastejo $80 \%$; DP: dia de pastejo; TL: Taxa de lotação (UA); PP: Período de pastejo; ${ }^{a b}$ letras diferentes na mesma linha, por dia de pastejo comparam as taxas de lotação, dentro de cada período de pastejo, e são diferentes $(p<0,01)$ pelo teste de Tukey. 


\section{COMPORTAMENTO INGESTIVO DIURNO DE VACAS GIROLANDAS}

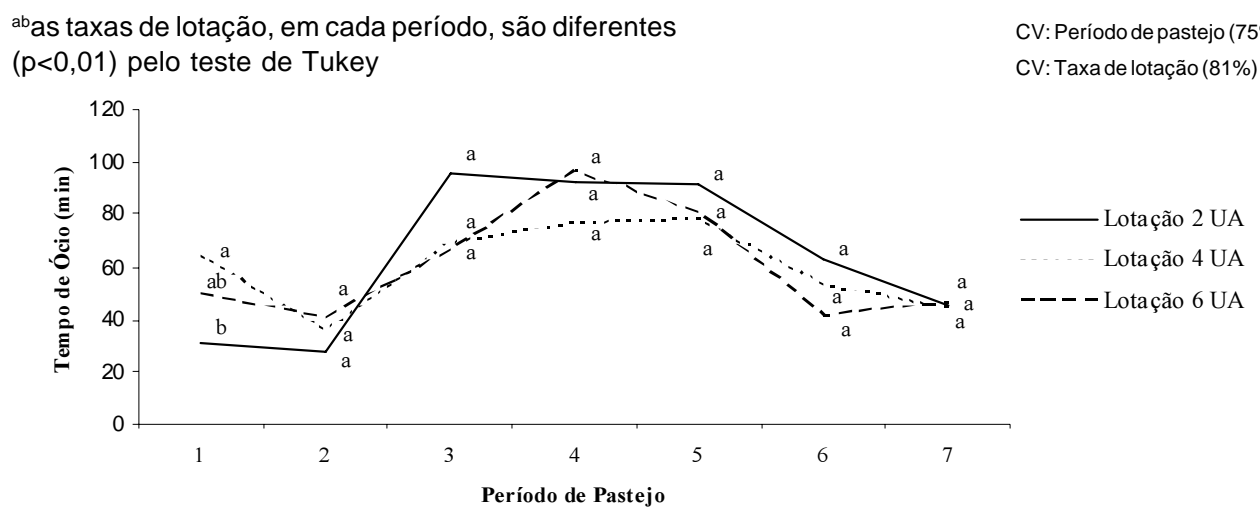

Figura 4. Tempo de ócio de vacas Girolandas em pastagem de B. decumbens, submetidas a três taxas de lotação, em diferentes períodos de pastejo. (Time of leisure of Girolando cows on pasture of $B$. decumbens, subjected to three stocking rates in different grazing periods).

observou-se maiores valores para o ITU e ITGU (Período 4 e 5), além da redução na pluviometria no período 3 , indicando que o aumento do tempo de ócio dos animais ocorreu como tentativa de minimizar o desconforto térmico.

O ócio é a atividade em que o animal não se encontra ingerindo alimento, água e ruminando. Esse tempo pode variar com as estações do ano, sendo maior durante os meses mais quentes (Hahn, 1999), nesse período os animais substituem as atividades de ingestão de alimento e ruminação pelo ócio, numa tentativa de reduzir a produção de calor metabólico (Costa, 1985).

Como anteriormente mencionado os valores de ITU e ITGU (figura 1), em todos os períodos de pastejo, apresentaram-se elevados e mesmo sob essa condição os animais dedicaram maior parte desse tempo diurno para atividades de pastejo (cerca de $75 \%$ ). Além disso, apesar do tempo de pastejo ter apresentado correlação negativa e significativa $(\mathrm{p}<0,01)$ com o ITU e ITGU, essas correlações não foram tão altas $(\mathrm{r}=$ 0,4843 e $r=0,4141$, respectivamente) (tabela I). Vale ressaltar que os animais usados no experimento foram formados a partir do cruzamento de animais Holandês x Zebu, inseridos na região há aproximadamente 40 anos, onde estes devem possuir certo grau de adaptação ao ambiente. Animais mantidos a muito tempo em ambiente tropical quase sempre desenvolvem uma adaptação suficiente para que suas reações à variação ambiental sejam diferentes do previsto (Silva, 2008), nas escalas de variação de ITU e ITGU, mostradas anteriormente.

De acordo com Pádua (1997), certa combinação de elementos climáticos, pode ou não ser favorável, dependendo do animal e das condições particulares nas quais ele se encontra. Os zebuínos são pouco afetados por temperaturas mais elevadas, uma vez que apresentam glândulas sudoríparas maiores, mais ativas e mais numerosas, quando comparados à maioria das raças européias (Manteca e Smith, 1994). Considerando também que o ambiente encontrava-se estressante para os animais, estes apresentaram produção de leite ordenhado $(5,00 \mathrm{~kg} /$ leite/dia) satisfatória para sistema de produção animal à pasto, além da ingestão de leite pelos bezerros durante o período que ficavam com as mães. A produção de leite preconizada para pastos adubados na Zona da Mata de Pernambuco é de 6 a 7 litros/vaca/dia (GonzálesSalamim, 1990). Possivelmente, os animais utilizaram o período noturno para recuperar 
o equilíbrio térmico. No entanto, proporcionar um ambiente de conforto ao animal é de grande importância para a promoção do bem estar destes, uma vez que a adoção de técnicas de manejo pode minimizar os efeitos do clima sobre os animais.

O tempo de ócio apresentou correlação positiva $(\mathrm{p}<0,01)$ com o tempo de outras atividades $(\mathrm{r}=0,3262)$, ITU e ITGU; e negativa $(\mathrm{p}<0,01)$ com o tempo de pastejo (tabela I). Vale ressaltar, que durante o período diurno observou-se que os animais dedicaram pouca quantidade de tempo para a atividade de ócio. Apesar de não ter sido observado o comportamento dos animais no período noturno, as menores temperaturas durante esse período, possivelmente favoreceram aos animais no processo de dissipação do calor.

O comportamento de ócio nos três dias de pastejo ocorreu de forma semelhante (períodos 1, 3, 5 e 6). Entretanto no período 2, o maior tempo de ócio foi verificado no primeiro dia de pastejo, enquanto que nos períodos 4 e 7, o maior tempo de ócio ocorreu no segundo dia (figura 5).

Durante os dias de pastejo na pastagem o animal vai fazendo ajustes em seu comportamento, dessa forma variações são esperadas. No primeiro dia de pastejo é o momento em que o animal tem à disposição maior quantidade de forragem, o que favorece a eles distribuírem de forma mais homogênea suas atividades.

Para a variável tempo de outras atividades, verificou-se interação significativa entre período de pastejo e taxa de lotação $(p=0,0032)$ e entre o período e dia de pastejo $(p=0,0001)$. Os animais nas três taxas de lotações apresentaram comportamento para outras atividades semelhantes (períodos 1 , $3,4,5,6$ e 7), com tempo médio de 10,25 minutos. No segundo período, o maior tempo de outras atividades foi apresentado pelos animais na lotação 6 (12,00 minutos).

O tempo de outras atividades inclui a atividade de locomoção. Vale destacar que os animais na pastagem com maior densidade animal, tendem a passar maior período em busca de áreas que possibilitem a realização de bocados potenciais.

Observou-se aumento no tempo destinado a esta atividade nos períodos 4 e 5 , nas três lotações avaliadas. Os animais como forma de minimizar o efeito da temperatura ambiente, destinaram menor quantidade de

${ }^{\mathrm{ab}}$ os dias de pastejo, em cada período, são diferentes $(p<0,01)$ pelo teste de Tukey

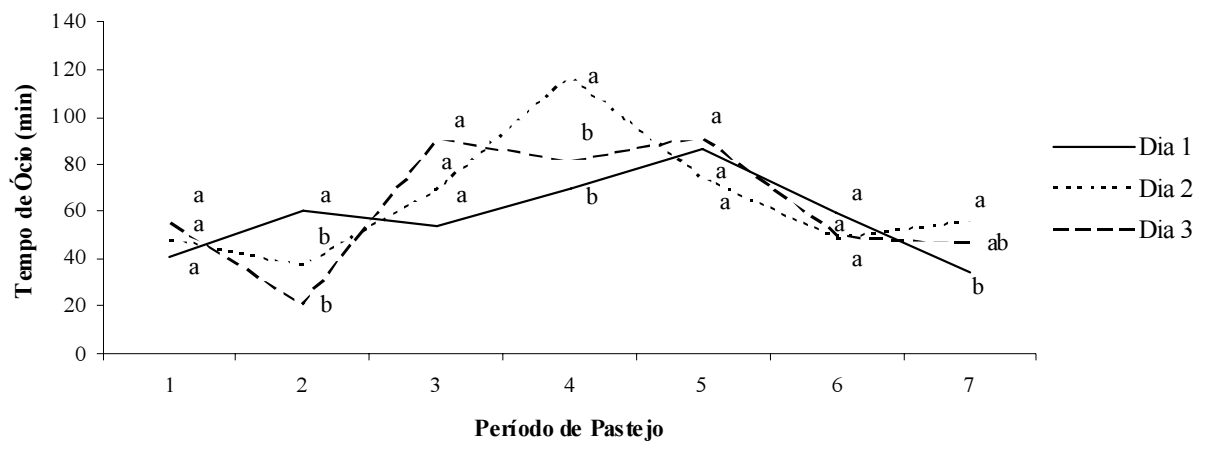

Figura 5. Tempo de ócio diurno de vacas Girolandas em pastagem de B. decumbens, nos diferentes períodos e dias de pastejo. (Daytime of leisure of Girolando cows on B. decumbens pasture, in different periods and days of grazing). 


\section{COMPORTAMENTO INGESTIVO DIURNO DE VACAS GIROLANDAS}

tempo diurno para atividades de pastejo, de forma que o tempo de ócio e de outras atividades tendeu a aumentar.

O tempo de outras atividades foi semelhante durante os três dias de pastejo na pastagem, nos períodos 3, 4, 6 e 7 (com valor médio de 8,85 minutos). Maiores tempo de outras atividades ocorreram no primeiro (20,00; 13,00 e 20,00 minutos, períodos 1,2 e 5 ) e segundo dia de pastejo (10,00 minutos, período 2$)$, momentos em que ocorrem a troca dos animais de piquete, onde mudanças no comportamento destes, em caráter de adaptação ao novo ambiente, são esperadas.

\section{BIBLIOGRAFIA}

Broom, D.M. and Fraser, A. 2007. Feeding. In: Farm animal behaviour and welfare. $3^{\mathrm{a}} \mathrm{ed}$. Baillière Tindall. London. pp. 79-98.

Buffington, D.E., Collazoarocho, A., Canton, G.H. and Pitt, D. 1981. Black globe-humidity index (BGHI) as confort equation for dairy cows. Trans. ASAE, 24: 711-714.

Carvalho, P.C.F., Prache, S., Roguet, C. e Louault, F. 1999. Defoliation process by ewes of reproductive compared to vegetative swards. International Symposium on the Nutrition of Herbivores, 5. Proceedings... San Antonio. USA.

Carvalho, P.C.F., Ribeiro Filho, H.M.N., Poli, C.H.E.C., Moraes, A. e Delagarde, R. 2001. Importância da estrutura da pastagem na ingestão e seleção de dietas pelo animal em pastejo. Reunião Anual da Sociedade Brasileira de Zootecnia, 38. Anais... SBZ. Piracicaba. pp. 853-871.

Carvalho, P.C.F. 2005. O manejo da pastagem como gerador de ambientes pastoris adequados à produção animal. Simpósio sobre manejo da pastagem, 22. Anais... Fealq. Piracicaba. pp. 7-32.

Carvalho, P.C.F. and Moraes, A. 2005. Comportamento ingestivo de ruminantes: bases para o manejo sustentável do pasto. Simpósio sobre manejo sustentável em pastagem. Anais... UEM. Maringá. pp. 1-20.

Costa, M.J.R. 1985. Aspectos do comportamento das vacas leiteiras em pastagens neo tropicais. Encontro Paulista de Etologia, 3. Anais... Ribeirão

\section{CONCLUSÕES}

O padrão comportamental diurno dos animais é afetado pela taxa de lotação, período de avaliação e dia de ocupação na pastagem. As atividades comportamentais apresentam relação entre si e com os índices de conforto térmico. Durante o período diurno os animais concentraram-se nas atividades de pastejo. No período chuvoso do ano os animais apresentam comportamento de pastejo semelhante, o que permitiu o uso de ambas as lotações, sem maiores danos ao comportamento dos animais neste período.

Preto. pp. 199-217.

Costa, C.O., Fischer, V., Vetromilla, M.A.M., Moreno, C.B. e Ferreira, E.X. 2003. Comportamento ingestivo de vacas jersey confinadas durante a fase inicial da lactação. Rev. Bras. Zootecn., 32: 418-424.

Damasceno, J.C., Bacari Jr., F. e Targa, L.A. 1999. Respostas comportamentais de vacas Holandesas com acesso a sombra constante ou limitada. Pesq. Agropec. Bras., 34: 709-715.

Farinatti, L.H., Poli, C.H.A.C., Monks, P.L., Fischer, V., Cella Júnior, A., Varela, M., Gabana, G., Sonego, E. e Campos, F.S. 2004. Comportamento ingestivo de vacas Holandesas em sistemas de produção de leite a pasto na região da Campanha do Rio Grande do Sul. Reunião Anual da Sociedade Brasileira de Zootecnia, 41. Anais...SBZ. Campo Grande.

Fraser, A. F. 1980. Comportamiento de los animales de la granja. Acribia. Zaragoza. $291 \mathrm{pp}$.

Fischer, V., Deswysen, A.G., Dutilleul, P. e Boever, J. de. 2002. Padrões da distribuição nictameral do comportamento ingestivo de vacas leiteiras, ao início e ao final da lactação, alimentadas com dieta à base de silagem de milho. Rev. Bras. Zootecn., 31: 2129-2138.

Gonzáles-Salamin, G.Y. 1990. Produção de leite em pastagens de Brachiaria na Zona da Mata de Pernambuco. Dissertação (Mestrado em Produção Animal). Universidade Federal Rural de Pernambuco. Recife, PE. 133 pp. 
Gordon, I.J. and Lascano, C. 1993. Foraging strategies of ruminant livestock on intensively managed grasslands: potential and constraints. International Grassland Congress, 17. Proceedings... Palmerston North. pp. 681-690.

Graig, J.V. 1981. Feeding problemas and vices. In: Domestic animal behaviour: causes and implications for animal care and management. Prentice-Hall. New Jersey. pp. 196-217.

Grant, R.J. and Albright, J.L. 1995. Feeding behavior and management factors during the transition period in dairy cattle. J. Anim. Sci., 73: 27912803.

Hahn, G.L. 1999. Dynamic responses of cattle to thermal heat loads. J. Anim. Sci., 77: 1020.

Hodgson, J. 1990. Grazing management: science into practice. Longman Handbooks in Agriculture. England. 203 pp.

Kelly, C.F. and Bond, T.E. 1971. Bioclimatic factors and their measurements. National Academy of Sciences. Washington. pp. 71-92.

Martin, P. and Bateson; P. 1986. Measuring behavior: an introductory guide. Cambridge University Press. Cambridge-UK. 242 pp.

Manteca, X. and Smith, A.J. 1994. Effects of poor forage conditions on the behaviour of grazing ruminants. Trop. Anim. Health Prod., 26: 129-138. Modesto, E.C., Silva, A.M., Santos, M.V.F., Brasil, L.H.A., Lira, M.A., Lira, C.C. e Dubeux Jr., J.C.B. 2008. Tempo de pastejo, taxa e número de bocados de vacas Girolanda em pastagem de Brachiaria decumbens Stapf, sob diferentes taxas de lotação. Reunião Anual da Sociedade Brasileira de Zootecnia, 45. Anais...SBZ. Lavras.

Montagner, D.B., Genro, T.C.M., Rocha, M.G., Elejalde, A.G., Bremm, C., Calegari, C., Macari, S. e Teixeira, T.B.C. 2003. Comportamento ingestivo de novilhas de corte em pastagem de milheto (Pennisetum americanum (L.) Leeke) manejada sob diferentes alturas. Reunião Anual da Sociedade Brasileira de Zootecnia, 40. Anais...SBZ. Santa Maria.

Pádua, J.T. 1997. Efeito do estresse calórico sobre o desempenho e variáveis fisiológicas em borregos confinados. Tese (Doutorado em Zootecnia). Faculdade de Ciências Agrárias e Veterinárias. Universidade Estadual Paulista.
Jaboticabal, SP. 82 pp.

Paranhos da Costa, M.J.R. e Nascimento Jr., A. F. 1986. Stress e comportamento. Semana de Zootecnia, 11, 1986. Anais... FMVZ/USP. Pirassununga. pp. 65-72.

Penning, P.D., Rook, A. and Orr, R.J. 1991. Patterns of ingestive behavior of sheep continuously stocked on monocultures of ryegrass or white clover. Appl. Anim. Behav. Sci., 31: 237-250.

Pires, M.F.A., Vilela, D. and Alvim, M.J. 2001. Comportamento alimentar de vacas holandesas em sistemas de pastagens ou em confinamento. EMBRAPA Gado de Leite. Minas Gerais. Boletim Técnico, 2. 2 pp.

Poli, C.H.E.C., Rochs, M.G., Pires, C.C., Farinatti, L.H.E., Montagner, D. and Bica, G. 2001. The effect of feed supplementation swards characteristics on the ingestive behavior of grazing ewes. International Grassland Congress, 19. Proceedings... Prod. Macro-media. Piracicaba. pp. 7-13.

Polli, V.A., Restle, J., Senna, D.B. e Almeida, R.S. 1996. Aspectos relativos à ruminação de bovinos e bubalinos em regime de confinamento. Rev. Bras. Zootecn., 25:987-993.

SAS Institute. 2001. Statistical analysis systems user's guide: version 8.2. $6^{\text {th }}$ ed. SAS Institute, Inc. Cary, NC. USA.

Silva, R. G. 2008. Biofísica ambiental: Os animais e seu ambiente. Jaboticabal. Funep. 393 pp.

Silva, J.F.C. e Leão, M.I. 1979. Fundamentos de nutrição de ruminantes. Livroceres. Piracicaba. 384 pp.

Silva, R.R., Silva, F.F., Prado, I.N., Carvalho, G.G.P., Franco, I.L., Almeida, V.S., Cardoso, C.P. e Ribeiro, M.H.S. 2006. Comportamento ingestivo de bovinos. Aspectos metodológicos. Arch. Zootec., 55: 293-296.

Swenson, M. J. 1996. Dukes fisiologia dos animais domésticos. $11^{\text {th }}$ ed. Guanabara Koogan. Rio de Janeiro. 798 pp.

Zanine, A.M., Santos, E.M., Parente, H.N., Ferreira, D.J. e Cecon, P.R. 2007. Hábito de pastejo de vacas lactantes Holandês $x$ Zebu em pastagens de Brachiaria brizantha e Brachiaria decumbens. Arq. Bras. Med. Vet. Zootecn., 59: 175-180. 